Mr Nada Čitaković, dipl. fizičak Vojna akademija,

Beograd
PRIMENA RAČUNARA U NASTAVI FIZIKE

UDC: $37.016: 53]: 004.4$

Rezime:

U radu je dat kratak osvrt na istraživanje nastave fizike, kao $i$ na upotrebu novih tehnologija, tj. računara u nastavi fizike. Pri korišćenju računara neophodno je primeniti metodičke zahteve koji bi trebalo da budu ispoštovani pri izradi softvera. Predloženo je $i$ šta bi se u toj oblasti moglo uraditi kako bi se primenom računara unapredila nastava.

Ključne reči: metodika, nove tehnologije, pravljenje softvera, unapređenje nastave primenom računara, obrazovanje u fizici.

\title{
COMPUTERS IN TEACHING PHYSICS
}

Summary:

This paper presents a short review of the state in physics education at the beginning of the $21^{\text {st }}$ century. Short reviews of investigations into physics teaching and application of new technologies, i.e. computers, in physics teaching are given as well. Different ways of computer applications are presented. Teaching method requirements are suggested in order to improve teaching by using PCs.

Key words: teaching methods, new technologies, software design, teaching improvement by PC usage, physics education.

\section{Istraživanje nastave fizike}

Grupa fizičara iz različitih zemalja sveta sprovela je tokom poslednje dve decenije istraživanje nastave fizike, čiji su rezultati značajan deo korpusa znanja o tome kako učenici uče fizi$\mathrm{ku}$, što je dobilo visok stepen konsenzusa [2]. Glavni zaključak je da su nastavni planovi ,milju široki i inč duboki“. Oni pokrivaju tako mnogo tema samo površno, sa intencijom da obezbede osnovu za kasnije studije. Ovi rezultati sada vode ka važnim nastojanjima da se projektuju novi nastavni planovi i programi, i koriste računari u nastavi fizike.

\section{Upotreba računara u nastavi fizike}

Završni ispiti učenika u zapadnim zemljama Evrope pokazali su najniži prosečni nivo znanja iz fizike i matematike. Statistički rezultati prikupljeni tokom godina neprekidno pokazuju negativne rezultate. Naime, učenici ne uče pojmove potrebne i neophodne za dobro razumevanje fizičkog sveta. Štaviše, završavaju razrede sa nekim fundamentalnim razumevanjem fizičkog sveta suštinski netaknutog. Njihovo učenje naučnih činjenica ostaje u učionici i kasnije nema uticaja na njihovo razmišljanje. Svako ko se interesuje za ovaj problem imao bi posla sa dva tipa pitanja: kako učenici uče fiziku i kako koristiti računare da se poboljša učenje. 
Alfred Bork (fizičar) i Sejmur Pejpert (matematičar) bili su pioniri u ovom tipu prilaza problemu. Bork je 1978. godine na adresu Američkog udruženja nastavnika fizike pod naslovom „Interaktivno učenje“" ustvrdio da smo na početku značajnije revolucije u obrazovanju, gde će računar biti instrument ove revolucije. Važan put učenja na svim nivoima, i u skoro svim oblastima, biće kroz interaktivno korišćenje računara. Mogućnosti za izradu softvera za nastavu fizike danas su mnogo veće nego što je to bilo ranije, jer su znatno poboljšani PC programi koji danas nastavnicima fizike daju mogućnost da i sami kreiraju nastavu uz pomoć računara (primena Power Point, Excel, 3Dmax i drugi). Tu je naravno i internet, koji daje mogućnost brzog nalaženja podataka i praćenja savremenih dostignuća u nauci. Postoje već napravljeni programi za nastavu fizike, koje treba koristiti, pre svega, kao nastavno sredstvo, kako bi se povećala motivacija učenika za nastavu fizike raznovrsnošću metodologija i tipa časa. Računar ne sme da bude jedino sredstvo pri učenju fizike.

\section{Računar kao nastavno sredstvo}

Kao nastavno sredstvo računar služi za praktične vežbe, podučavanje, modeliranje fizičkih pojava i procesa, testiranje učenika, rešavanje zadataka. Metode koje se koriste su:

- monološka metoda - najniži nivo nastave. Svodi se na iznošenje gradiva. Student nema mogućnost da pita i da sam učestvuje u stvaranju nastavne situacije. Smanjena je mogućnost njegovog kreativnog razvoja, a aktivnost se ograničava na pažljivo praćenje izlaganja novih sa- držaja putem monitora i rešavanje zadataka koji su vezani za određenu nastavnu jedinicu. Nažalost, ovaj način učenja pomoću računara je najrasprostranjeniji;

- dijaloška metoda - viši nivo učenikove aktivnosti u procesu učenja. Centralno mesto kao oblik podučavanja ima dijalog, a u kojem student daje odgovore od kojih zavisi dalji tok komunikacija;

- problemski tip časa - još viši oblik učenja pomoću računara, koji podrazumeva rešavanje problema. Student unosi u računar informacije o metodi rešavanja zadataka koje je odabrao, a odgovor računara je podatak o posledici do koje dovodi odabrani postupak;

- metoda podučavanja. Za ovaj oblik učenja karakterističan je odnos između studenta i računara u kojoj računar ima ulogu strpljivog tutora. Osnovna odlika ovakvog učenja je model tipa pitanje - odgovor. Pripremljene informacije mogu biti izložene i prilagođene bilo kom sistemu učenja. To je program koji najviše vodi ka individualizaciji nastave.

\section{Računar - zamena za nastavnika}

Gotovi programi pružaju mogućnost učenja kod kuće bez prisustva nastavnika. Ovakvi programi moraju biti sa što manje grešaka $i$, ukoliko je to moguće, interaktivnog karaktera. Potreba za ovim je jasna, student ne sme da nauči pogrešno interpretirane sadržaje i kada mu je potrebna pomoć za razumevanje određene materije računar „mora biti spreman“ da pruži traženu pomoć. Ovakav vid nastave gde računar ima ulogu nastavnika zastupljen je u svetu, a trebalo bi ga koristiti samo ukoliko prisustvo nastavnika nije moguće. 


\section{Neke prednosti korišćenja računara u nastavi}

Prednosti su sledeće:

a) Interaktivnost

Računar omogućava svakom studentu da ima aktivnu ulogu u procesu učenja, za razliku od pasivne uloge knjige. Student više nije posmatrač već aktivni učesnik u procesu učenja.

\section{b) Individualna pažnja}

Nastavnici znaju da su studenti različiti, tj. nemaju svi isto predznanje i ne uče na isti način. Međutim, mnogi od naših konvencionalnih prilaza obrazovanju koriste rigidne procedure iste za sve studente i ne dozvoljavaju uzimanje u obzir ovih razlika. Prednost računara je u tome da se dobrim softverom može individualizovati podučavanje. Štaviše, pošto svi studenti ne uče istom brzinom, tj. potrebno im je različito vreme da prođu kroz gradivo, računar im to takođe omogućava. Sledeći važan faktor $\mathrm{u}$ napredovanju upotrebe kompjutera $\mathrm{u}$ obrazovanju je povećanje snage kompjutera, i prikladnosti za implementiranje novih načina učenja.

\section{Različiti načini korišćenja računara}

Danas postoje različiti načini korišćenja računara za predavanje i učenje fizike, a to su: simulacija, multimedija, telematika, virtuelna realnost i računarske laboratorije [1].

\section{Simulacija kao način učenja}

Pod simulacijom se podrazumeva predstavljanje fizičkih pojava i procesa brojevima, simbolima ili živim slikama. Mogu se simulirati realna ili nerealna stanja. U nastavi fizike su važne sledeće simulacije: simulacija fizičkog eksperimenta, simulacija procesa u oblastima atomske, nuklearne fizike i fizike elementarnih čestica. Ove simulacije su veoma korisne kod onih procesa u kojima se ne mogu pri laboratorijskoj vežbi zapaziti suštinska dešavanja u materiji (alfa, beta raspad, određivanje energije alfa čestica pomoću tragova, nuklearna fisija, fuzija, Komptonov i fotoefekat, sudari elementarnih čestica i drugo). Međutim, u nekim slučajevima je korisnije izvršiti eksperiment nego simulirati proces na računaru (gasni zakoni, Omov zakon, itd. tu računar može da služi za prikupljanje i obradu rezultata merenja). Znači, simulacije ne bi trebalo nikada potpuno da zamene realnost, ali su ekstremno upotrebljive kada se proučavaju eksperimenti koje je nemoguće uraditi praktično (zato što su veoma skupi, veoma opasni, vrlo brzi, vrlo spori, itd.).

\section{Multimedija}

Ovaj modalitet je baziran na konceptu hiperteksta, odnosno hipermedija. Reč multimedija znači da moduli uključuju razne elemente kao što su: tekstovi, animacije slika, kombinacija zvuka, grafike i videoklipova. Izreka „slika je hiljadu reči vredna“" ovde dolazi do potpunog izražaja, što znači da informacija treba da bude što je moguće vizuelnija. Modul hiperteksta ima nekoliko internih linkova i čitalac nema potrebu da sledi linearni ili sekvencijalni put kroz modul, već može lako da izabere one delove modula koji su mu od interesa u tom trenutku. Ključne karakteristike multimedija su interaktivnost i fleksibilnost, tj. mogućnost uno- 
šenja komandi i sposobnost da se izabere put unutar pribavljenih informacija. Prednosti multimedija su široko preporučene, pošto su i u skladu sa nekim pedagoškim teorijama, jer su ovi faktori potrebni za dobro učenje. Multimedija može biti on-line ili off-line, zavisno od načina na koji je informacija ponuđena.

\section{Telematika}

Telematika je sprega telekomunikacija $i$ automatske obrade informacija. Internet, mreža svih mreža, neiscrpni je izvor znanja, koji daje mogućnost brzog i efikasnog prikupljanja najsvežijih informacija iz svih oblasti nauke. Traganje po internetu omogućava nastavniku da prati sva nova zbivanja i otkrića u nauci, čime se i njegovo znanje proširuje, a ne završava sticanjem diplome. Nastavnik bi trebalo da pomogne studentu na različite načine. Na primer, u pretraživanju i selekciji informacija relevantnih za zadati cilj, usred ogromnog i nesređenog informacionog „okeana“. Pod ovim okolnostima njegova uloga neće biti centralna, (jedan govornik i mnogo slušalaca), već će postati periferna (mnogo govornika i mnogo slušalaca). Nastavnik neće biti više jedini posednik i dobavljač informacija, već će postati ekspert i konsultant za razmatranje materije $i$ rešavanje problema. Internet postaje najveća i najživlja od svih biblioteka, a zidovi učionica srušeni su direktnom komunikacionom vezom sa tim izvorom. U isto vreme, internet predstavlja veliki korak ka većoj demokratizaciji obrazovanja sa podjednako datim prilikama za svakog učenika, nezavisno od toga gde se nalazi. Mnogi kursevi egzistiraju na Web-u. Dobar primer upotrebe interneta za predavanje fizike je Kurs opšte fizike baziran na JAVA jezi$\mathrm{ku}$, koji ima Davidsson college, North Caroline, USA [5].

\section{Virtuelna realnost}

Virtuelna realnost je snažan vizuelni alat koji pomaže učenicima da stvore svoje predstave o svetu koji ih okružuje. Projekat „Science Space“ je dobar primer primene virtuelne realnosti u učenju. Sastoji se od niza virtuelnih svetova, projektovanih da pomognu učenicima u savladavanju izazovnih pojmova u fizici. Projekat je zajednički istraživački poduhvat George Mason University, University of Houston i NASA Jonson Space Centar, USA [6]. „Science Space“ se sastoji od tri virtuelna okruženja:

- Njutnov svet (pruža okruženje za istraživanje kinematike i dinamike jednodimenzionog kretanja),

- Maksvelov svet (podržava istraživanja elektrostatike) $\mathrm{i}$

- Paulingov svet (omogućava proučavanje molekulskih struktura preko različitih prezentacija).

\section{Računarske laboratorije}

Fizika je eksperimentalna nauka i računar je već našao mesto u fizičkoj laboratoriji. Računar je nastavno sredstvo $u$ kabinetima fizike, gde prikuplja merne podatke i obrađuje ih (grafičko predstavljanje i dr.). Međutim, bogatstvo računarskih laboratorija i odgovarajućih pripadajućih alata za modeliranje moglo bi imati važniji uticaj na predavanja i učenje fizike. Korišćenjem ovih alata fizika se 
može učiniti mnogo manje zastrašujućom za učenike sa manjim matematičkim sposobnostima. Mogu se koristiti za povećanje sposobnosti za rešavanje kompleksnih problema. Možda je najvažnija mogućnost kreirana ovom tehnologijom omogućavanje učenicima da preduzmu svoja sopstvena originalna istraživanja. Mnogo je toga što je pogrešno $u$ nastavi fizike. Jedno je to što studenti samo uče, ali ne učestvuju u nastavi na zadovoljavajući način. Trebalo bi da imaju priliku da rade realne fizičke eksperimente i da potpuno učestvuju u učenju novih činjenica o svetu prirode. To omogućava ne samo jaku motivaciju, već predstavlja jedini način da dobro (tačno, precizno) razumeju fiziku, bez obzira na to da li će ih njihova karijera voditi u prirodne nauke ili neće.

\section{Kratak pregled nekoliko gotovih softvera za nastavu fizike}

$\mathrm{Na}$ našem tržištu se pre par godina pojavio program ,Super Tutor - Physics 1 i 2 " [7], koji je Staford Studyware izradio 1996. godine. Sam naziv govori o metodi koju ovaj program koristi. Međutim, iako je to tutorski tip softvera, postoje i dobre strane ovog programa. Ubačene su video sekvence koje unose izvesnu dinamiku i drže na taj način pažnju studentima. U okviru programa postoje i animacioni delovi u kojima se traži da se sam učenik angažuje u rešavanju nekih zadataka. Na ovaj način proces učenja postaje interaktivan. Autori ovog programa su dali i mogućnost provere znanja. Naime, ponuđeni su računski zadaci koje student treba da reši i koje može da proveri. Veliki nedostatak ovog programa je što je potpuno zatvoren, tj. ne dozvoljava korekciju nastavnika koji ga koriste i ne pruža mogućnost „osvežavanja“ sadržaja. Samim tim i učenik ponekad dobija zastarelu informaciju i neku pogrešnu, $\mathrm{s}$ obzirom na to da su se u programu potkrale i neke materijalne greške, koje bi inače mogle da se isprave.

Drugi CD koji se takođe mogao kupiti kod nas je Exploring Physics [8], koji je izašao 1996. godine i predstavlja malo konzervativniji pristup nastavi. Podeljen je na sledeće delove: fizički fenomeni, merenja, fizički zakoni, kinematika i dinamika, fenomeni ravnoteže, energija i transformacija, elektricitet $i$ atomska fizika. Slično prethodnom programu i ovde se iz menija ulazi u određenu oblast. Svaki deo sadrži tekst sa odgovarajućom teorijom, a u posebnom odeljku može se animirati neka pojava kroz kratak video spot, ili odgovarajuću sliku. Postoji mogućnost provere stečenog znanja, na taj način što kroz ubacivanje brojnih vrednosti u već ponuđene tabele učenik proverava razumevanje određenog zakona. Upravo je tu mana ovog programa, što se matematizuje fizička pojava i što učenik ne stiče sposobnost merenja fizičkih veličina i na kraju ne upoznaje se ni sa aparaturom sa kojom vrši merenje odgovarajuće fizičke veličine. Osim ovih mana u poređenju sa prethodnim može se zaključiti i da su slike i animacije znatno lošije. Metodički gledano ima i tu dosta nedostataka, kao na primer pretrpanost strane informacijama, na istom mestu se nalaze i tekst, animacije, meni i eksperiment, a i računski zadatak. Ovaj program bi bio koristan isključivo pri proveri znanja naučenog sadržaja, a nikako u procesu učenja. Dakle, koristan je samo za kućnu upotrebu učenika. 
Razvijeniji pristup primene računara $\mathrm{u}$ nastavi dat je u programskom paketu ADV Physics [9], u kojem je računar i nastavno sredstvo i nastavni objekat. U ovom programu otišlo se najdalje ka individualizaciji nastave. Kurs je atraktivan i pristupačan za učenike sa različitim nivoima interesovanja. Napravljen je tako da se vidi veza fizičkih zakona sa svakodnevnim životom. Prezentirane su sledeće aktivnosti u ovom kursu: demonstracija vežbi koje izvodi nastavnik (date kroz kratke filmove), izlaganje studenata, eksperiment za studente i kućni eksperiment, a realizovane su uz pomoć postera, slika, filmova i sl. Specifičnost kursa je što postoji deo predviđen i za aktivnost nastavnika. Dato je detaljno uputstvo nastavnicima za korišćenje ovog programa, interaktivni Web-site, a od nastavnika se očekuje da pruži maksimalnu pomoć studentima.

$\mathrm{Za}$ astronomiju, koja je sada u okviru fizike za četvrti razred srednje škole, dat je niz sjajno urađenih softvera, npr: Red Shift [10] i Deep space explorer [11]. Ovi programi, sem što su dobro organizovani, poseduju ogroman broj snimaka nebeskih tela koji su napravljeni sa mnogih svemirskih ekspedicija i sa velikih zemaljskih satelita. Snimci su još umetnički dorađeni i pružaju izuzetno zadovoljstvo posmatraču. Sem fotografija nebeskih tela tu se mogu videti animacije kretanja tih tela (obrtanja tela oko svoje ose, gde se vidi trodimenzionalnost i celovitost objekta), zatim poprečni preseci tela, sa detaljnim oznakama svih bitnih podataka. Pored toga, data je i karta neba gde se može videti raspored nebeskih tela i odrediti njihov položaj u sfernim nebeskim koordinativnim sistemima. Najlepši deo ovog programa predstavljaju kratki animacioni filmovi o naučnim pretpostavkama o nastanku svemira, Sunčevog sistema i drugi. Jednom rečju, to je jedan od najbogatijih edukativnih programa koji su se do sada pojavili.

Prijatno iznenađenje predstavljala je i pojava naših CD-ova sa programima iz fizike, to su Fizika 1 i Fizika 2, koje je izdala Kvark medija [12], 1999. godine. Programi su izrađeni prema programima za gimnaziju i obuhvaćeni su svi vidovi nastave: fenomenološki pristup fizičkim pojavama kroz animacione slike, potom teorijski pristup, eksperimentalne vežbe i na kraju računski zadaci. Prednost ovih programa u odnosu na do sada pomenute je što su na veoma atraktivan i savremen način predočene oblasti iz fizike kroz interaktivan vid nastave, što su inače savremeni standardi (zahtevi) metodike nastave. Najinteresantniji deo ovih programa su eksperimentalne vežbe. U nedostatku materijalnih sredstava i nemogućnosti nabavke skupih učila (kojih inače nema na našem tržištu) gimnazije bi mogle ovim CD-ovima taj problem da reše na zadovoljavajući način. Prednost ovakvih „eksperimentalnih vežbi“ je i u tome što se vežbe mogu raditi individualno, a ne u grupama; što postoji mogućnost većeg broja ponavljanja iste vežbe dok se ne dobiju zadovoljavajući rezultati i što studenti lakše mogu da uoče napravljene greške pri merenju.

\section{Drugi vidovi primene računara u nastavi}

Do sada su pomenuti već izrađeni programi za nastavu za koje je dovoljno da nastavnik ili student znaju da rukuju računarom i da puste program. Međutim, 
pored toga, računari se mogu koristiti i na drugi kreativniji način. Zahvaljujući razvoju mikroračunarskog sistema i velikog broja naprednih programa, kao što su Power Point, Flash, Excel (programi za kreiranje sadržaja u vidu slajdova i tabela), a takođe programi za obradu slika Adobe Photoshop i Point, ACD See-program za vizualizaciju većeg broja slika $u$ vidu dokumenata, nastavniku je data mogućnost da sam napravi program koji će sadržati sve potrebne metodički najefikasnije elemente edukativnog procesa. Ovakav vid nastave, gde računar postaje nastavno sredstvo, otklanja sve nedostatke već gotovih korisničkih programa: greške se mogu uvek ispraviti, sadržaji se mogu dopuniti novim i svežim informacijama, a prisustvo nastavnika daje mogućnost dodavanja informacija i tumačenja nejasnoća $\mathrm{u}$ obrazovnom procesu. Naravno, neiscrpni izvor znanja je svakako internet.

\section{Mogućnosti i karakteristike Power Point-a}

Program Power Point (PP) omogućava crtanje linija i animaciju, što može da olakša nastavnicima, a i studentima obradu veoma suvoparnih, ali bitnih nastavnih jedinica. Prednosti rada sa PP su sledeće: jasnoća vizuelne prezentacije, preciznost grafičke predstave, bogatstvo boja, postepenost u prikazu detalja na slici (naknadno ubacivanje detalja), zvučni efekti za podršku animacije, naracija, interaktivan rad sa studentima, ušteda vremena za crtanje (u toku koga drastično pada pažnja slušaocima) i laka dopuna i priprema slajdova po uočavanju grešaka ili „slabih“ mesta.
Nedostaci su: vreme potrebno za pripremu nije zanemarljivo, zatamnjena prostorija i neophodnost tehničke opremljenosti, smanjen vizuelni kontakt sa studentima, vreme potrebno za pripremu ,tehnike“.

$O$ efikasnosti same nastave se ne može još ništa reći, jer je za to potrebno daleko obimnije metodičko istraživanje. Ono što je pouzdano zapaženo je mnogo veća motivisanost i angažovanost studenata na časovima. Mogućnosti korišćenja PP su velike i mogu nastavniku da pomognu u održavanju kvaliteta nastave. Ipak, ne treba prihvatiti ovakav vid nastave kao alternativu klasičnom, PP treba uvesti u nastavu kao vizuelni nastavni program koji može da, uz žive slike, ilustruje priču nastavnika. Pri pravljenju PP prezentacije, za ovaj vid nastave treba voditi računa o sledećem:

- slajd ne sme da bude pretrpan informacijama; treba da sadrži najbitnije delove nastavne jedinice - ono što bi trebalo da učenik zapamti na času;

- izbor pozadine slajda mora biti neupadljiv;

- slajd treba da čini jednu logičku celinu, blisku misaonim procesima učenika i da svojim audio i vizuelnim sadržajem pomogne u lakšem i bržem razumevanju i memorisanju fizičkih pojava;

- slajd ne sme da ima nedorečenosti, jer u slučaju pasivnog učešća nastavnika mogu da se dese propusti koji mogu da imaju za posledicu i pogrešno izvođenje zaključaka.

\section{Zaključak}

U svetu postoje organizacije i projekti na izradi softvera za nastavu fizike. Najdalje se otišlo na izradi programa koji 
su u učenju fizike služili za praktične vežbe, testiranja i rukovanje kursevima, za automatska merenja. Kod nas ne postoji strategija na nivou zemlje koja bi okupila timove stručnjaka koji bi se bavili primenom računara u nastavi. Prepušta se pojedincima entuzijastima ili manjim grupama da sami prave softvere, a pri tome nema koordinacije između njih.

$\mathrm{Na}$ osnovu analize pomenutih programa u svetu i kod nas može se izvesti zaključak da u našoj zemlji postoje izuzetno kreativni i sposobni programeri koji su počeli sa ogromnim entuzijazmom i kreativnošću da izrađuju softvere za nastavu, ali je očigledno da nema podrške za to, jer su takvi projekti zaustavljeni. Pohvalno je i to da je Prirodno-matematički fakultet (Odsek za matematiku i informatiku) u Novom Sadu organizovao seminare o upotrebi računara u nastavi i pruža mogućnost obrazovanja nastavnika na poslediplomskim studijama. $\mathrm{S}$ tim $\mathrm{u}$ vezi, trebalo bi što pre izraditi iscrpnu studiju o mogućnostima primene računara u nastavi na nivou države.

Može se zaključiti da je za nastavu fizike najvažnija raznovrsnost primene nastavnih metoda i vidova nastave, nastavnih učila i sredstava, kako bi se održavala motivisanost studenata za ovaj predmet.

\section{Literatura:}

[1] Fiolhais C., Trindade J. A.: Use of Computers in Physics Education, Proceedings of the „Euroconference ' 98 - New Technologies for Higher Education", Aveiro, 1998

[2] Esquembre F.: Computers in physics education, Computer Physics Communications 147 (2002) 13-18.

[3] http:// www. physik.uni - bremen.de / physics.education / niedderer / projects / cip.html.

[4] http:// www. physik. uni - bremen.de / physics.education / niedderer / projects / cip / modeling 2. html.

[5] http.//www.davidson.edu/

[6] http:// www. jsc. nasa. gov / cssb / vr / Science Space /

[7] Staford Studyware, Tutarial physics, e-mail: tutored@stanfordsw.com

[8] FINSON S.R.L, Exploring: Physics, via Montepulciano 15 , 20124, Milan, Italy.

[9] Institut of Physics Publishing, Advancing Phiysics, Bristol. [10] Maris Multimedia, Red Shft 1, 2, 3 i 4.

[11] SPACE, com Canada inc., Deep Space Explorer, suppart@starynight.com

[12] Kvark media, Fizika 1 i Fizika 2, Beograd, Bulevar mira 70, e-mail: kvark@EUnet.yu 